\title{
Bio-Treatment of Flavour Effluent and its Reuse for Growth of Ornamental Plant CHRYSANTHEMUM SP
}

\author{
C. M. Noorjahan ${ }^{1}$, Sheeba Ali Siddiqui ${ }^{2}$ \\ ${ }^{1}$ Corresponding Author: C. M. Noorjahan, Assistant Professor, PG \& Research Dept. of Zoology, Justice Basheer Ahmed Sayeed College \\ for Women (Autonomous), Chennai - 600 018, Tamil Nadu, India
}

${ }^{2}$ Ph.D. Research Scholar, PG \& Research Dept. of Zoology, Justice Basheer Ahmed Sayeed College for Women (Autonomous), Chennai600018 , Tamil Nadu, India

\begin{abstract}
An investigation was carried out to propose an useful approach towards the bio-treatment of flavour effluent using fungus and reuse of fungus treated flavour effluent for growth of ornamental plant, Chrysanthemum sp by studying the growth parameters such as shoot length, root length, number of sub roots etc. Aspergillus sp was selected to degrade the untreated flavour effluent. The degradation of 100\% untreated flavour effluent using fungus Aspergillus sp was carried out for a period of 96 hrs, and the bio-treated sample was reused for the growth of ornamental plant, Chrysanthemum sp. The results of analysis of degradation of the effluent revealed that colour and odour of $100 \%$ untreated sample has changed to pale yellow and odorless condition after treatment and the growth rate of ornamental plant, Chrysanthemum sp is increased in bio-treated and control samples compared to untreated sample. The study revealed that native fungus, Aspergillus sp. played a key role in the degradation of untreated flavour effluent and the treated water can be utilized for growth of ornamental plant as evidenced in the present work.
\end{abstract}

Keywords: Flavour effluent, Degradation, Aspergillus sp, reuse, Chrysanthemum sp.

\section{Introduction}

The pollution of water courses are due to discharge of waste from different industries such as tanneries, pulp and paper, sago mills, distilleries, sugar factories, dying industries, textile mills, fertilizers, petroleum and chemical industries, sewage waste water, food processing industry etc (Jamuna, 2008). Flavour industry is one of the food processing industry that cause water pollution. Flavour effluent are generated after the processing of flavour. Flavour effluent when discharged into water bodies alter the physical, chemical and biological characteristics of water and depletes the dissolved oxygen, increases alkalinity, solids etc. It also leads to production of odours, sludge deposits and unsightly floating scum. Discharge of such effluent with high pollutional load into any water bodies will be deletrious not only to aquatic organisms but also to other organisms and human beings. (Thakur, 2006) So it has become essential to treat the waste to a certain degree prior its disposal. Though there are many physical, chemical and biological means of waste water treatment are available, scientists have found that in managing certain wastes, the best option is microbiological treatment which is more efficient and consumes no energy. Since the complete degradation of organic chemicals in the natural ecosystem is primarily carried out by micro-organisms, bio technological application uses microbes or their enzymes for waste treatment (Ninnekar, 1992). Hence the present study was undertaken to degrade the untreated flavour effluent using native fungus, Aspergillus sp and to use bio-treated sample for agriculture-growth of ornamental plant, Chrysanthemum $\mathrm{sp}$.

\section{Materials and Methods}

Untreated flavour effluent was used as the material in this study. The untreated sample was collected in polythene containers ( 5 litres capacity) from the point where in all the effluent were discharged together from flavour company situated in Chennai, Tamil Nadu, India. They were brought to the laboratory with due care and stored at $25^{\circ} \mathrm{C}$ for further analysis.

Flavour effluent of about 1 litre was collected in sterile bottles and brought to the laboratory. Analysis of fungi was carried out on the same day. Untreated flavour effluent was diluted to $10^{-1}$ using sterile distilled water. $1 \mathrm{ml}$ of diluted sample was cultured on Malt Extract Agar Medium (MEA) following pour plate method. Fungal species developed on the medium was observed. The fungal colonies grown on Malt Extract Agar Medium were subcultured on Potato Dextrose Agar (PDA) slants. The fungi were stained with lactophenol cotton blue and identified as Aspergillus sp using the Manual of Onions et al. (1981).

Degradation of untreated flavour effluent using Aspergillus sp was carried out by following the procedure of (Kannagi, 2007). Mycelial mats of Aspergillus sp grown separately in liquid culture were recovered, washed with sterile distilled water and approximately 10 gms (fresh weight) mycelia of fungus was transferred to $100 \%$ of untreated flavour effluent in a conical flask. Conical flask with effluent and fungus (experimental) were incubated at $30 \pm 0.5^{\circ} \mathrm{C}$ for 96 hours using rotary shaker at $2000 \mathrm{rpm}$. After incubation the samples were centrifuged at $5000 \mathrm{rpm}$ for 20 minutes. Control (conical flask with untreated flavour effluent without fungus) was also run simultaneously. 


\section{International Journal of Science and Research (IJSR) \\ ISSN (Online): 2319-7064}

Index Copernicus Value (2015): 78.96 | Impact Factor (2015): 6.391

Colour of the untreated flavour effluent was observed visually and recorded. The odour of untreated flavour effluent was detected by smelling directly from the samples collected in bottle. Physico-chemical parameters of untreated flavour effluent before and after degradation using native fungus, Aspergillus niger were carried out by following the method of APHA (1995).

After degrading the untreated flavour effluent using Aspergillus sp for $96 \mathrm{hrs}$, the degraded water were reutilized for growth of plants such as ornamental plant, Chrysanthemum sp. by following the procedure of Mehaytaab (2008).

The seeds of ornamental plant, Chrysanthemum sp were procured from a local nursery located in Chennai for the germination and growth in flavour effluent. The seeds of ornamental plant, Chrysanthemum sp. were washed with mercuric chloride solution for 2 minutes and then thoroughly washed in distilled water. Each earthen pot filled with farm yard manure was sown with 10 seeds, allowed to germinate by using equal volume of untreated and bio-treated samples of flavour effluent. One set was irrigated with water as control. Five replicates were maintained for each concentration. The vegetative features (i.e) shoot and root length, number of leaves and subroots of the above plant were recorded on $10^{\text {th }}, 20^{\text {th }} \& 30^{\text {th }}$ day of growth.

\section{Results and Discussion}

The results of degradation (before and after) of $100 \%$ untreated flavour effluent using Aspergillus sp for $96 \mathrm{hrs}$ are depicted in Table 1. The results of the study revealed that colour of the untreated flavour effluent before degradation was brick red and odour was unpleasant. This colour and odour could be due to decomposition of organic or inorganic matter (Singh et.al.1998). A large number of pollutants can impart colour, taste and odour to the receiving water, thereby making them unaesthetic and unfit for domestic consumption (Goel, 1997). But after biodegradation of the effluent for 96 hrs, the colour changed to pale yellow with almost odourless condition. This may be due to the action of microbes Aspergillus sp, which decomposed the toxic pollutants present in the effluent and made the change in colour and odour of the effluent. (Krishna priya, 2010).

$\mathrm{pH}$ of the flavour effluent was found to be alkaline $(7.5 \pm$ 0.08 ) before degradation. Highly alkaline water if consumed would affect the mucous membrane and may cause metabolic alkalosis The toxicity of certain substances present in water may be enhanced due to their interaction with high or low levels of $\mathrm{pH}$ prevailing which may further be detrimental to aquatic organisms (Goel, 1997). After biodegradation, $\mathrm{pH}$ of untreated flavour effluent changed to almost neutral $\mathrm{pH}$ (7.0 \pm 0.3 ) which may be due to accumulation of organic acids and also indicating the efficiency of the microbes to biodegrade the effluent. This is in agreement with the reports of Noorjahan et al. (2004).

Untreated flavour effluent showed higher level of Electrical conductivity $(1673 \pm 0.81 \mu \mathrm{mhos} / \mathrm{cm})$ than the permissible limits of CPCB (1995), which could reflect the presence of organic and inorganic substances and salts that would have increased the conductivity (Robinson and Stokes, 1959).Electrical conductivity of biotreated effluent showed reduced level after biodegradation $(700 \pm 3.39 \mu \mathrm{mhos} / \mathrm{cm})$. High amount of TSS was found in the effluent $(378 \pm 1.06$ $\mathrm{mg} / \mathrm{l})$ which may have adverse effects on aquatic flora and fauna and reduce the diversity of life in aquatic system and promote depletion of oxygen and sliting in ponds during rainy season (Goel, 1997).TSS of flavour effluent was reduced to a maximum (70 $\pm 6.81 \mathrm{mg} / \mathrm{l})$ using, Aspergillus sp. High levels of TDS was found in the effluent $(2500 \pm 1.49 \mathrm{mg} / \mathrm{l})$, this may be due to high salt content and also renders it unsuitable for irrigation hence further treatment or dilution of the effluent would be required (Goel, 1997) but after biodegradation of effluent for $96 \mathrm{hrs}$, maximum reduction of TDS $(600 \pm 1.06$ mg/l) was recorded using Aspergillus sp. Since TSS and TDS are the major pollutants, the results of above biodegradation process are encouraging and scale up studies for continuous treatment of waste water at pilot scale is required. The information generated would help to scale up the process and assess the economic feasibility of the technology.

The results of present study revealed high levels of BOD $(292 \pm 4.7 \mathrm{mg} / \mathrm{l})$ in the flavour effluent due to the presence of considerable amount of organic matter. High BOD levels have also been reported for effluent discharged from tanneries (Kulkarni, 1992). The presence of organic matter will promote anaerobic action leading to the accumulation of toxic compounds in water bodies (Goel, 1997). But on biodegradation for $96 \mathrm{hrs}$, the results showed that BOD level was very much reduced $(35 \pm 3.68 \mathrm{mg} / \mathrm{l})$ using Aspergillus sp. High levels of COD $(450 \pm 1.29 \mathrm{mg} / \mathrm{l})$ in the effluent were recorded before degradation process. This indicates that the effluent is unsuitable for the existence of aquatic organisms due to the reduction in dissolved oxygen content (Goel, 1997). After biodegradation, the COD levels was reduced $(150 \pm 3.09 \mathrm{mg} / \mathrm{l})$.

Aspergillus sp have potential use as biosorbents for removal of heavy metals particularly chromium from industrial waste waters which is in accordance with the reports of Akthar and Mohan (1995). Kannagi (2007) used Aspergillus niger for the degradation of brewery effluent. According to Adrianazilly et.al. (2011). Ganoderma lucidum has the potential to decolourize industrial effluent. Number of researches had been carried out concerned with degradation of industrial effluent using Aspergillus sp. They attempted with sludge and water for agricultural purposes. Shafiquzzaman Siddiquee et.al. (2015) removed heavy metal contaminants from wastewater using the potential filamentous fungi biomass. Ihsan flayyih hassan et.al. (2015) studied efficiency of some filamentous fungi to treatment of effluent petroleum wastewaters refinery and suggested fungi helps in reduction of refinery contaminants from effluent. Kowsalya et.al.(2015) studied physicochemical characterisation of brewery effluent and its degradation using native fungus Aspergillus niger and suggested that biodegradation using Aspergillus niger is the most promising technique for the treatment of brewery effluent.

The results of the growth of ornamental plant Chrysanthemum sp are depicted in Table 2. The growth of ornamental plant Chrysanthemum sp such as (shoot length, 


\section{International Journal of Science and Research (IJSR) ISSN (Online): 2319-7064 \\ Index Copernicus Value (2015): 78.96 | Impact Factor (2015): 6.391}

root length, number of subroots, and number of leaves) were measured and recorded on the $10^{\text {th }}, 20^{\text {th }}$ and $30^{\text {th }}$ day.

On the $10^{\text {th }}$ day, shoot length $(7 \mathrm{~cm} \pm 0.08)$, root length (4 $\mathrm{cm} \pm 0.01)$ no. of subroots $(5 \pm 0.71)$, no. of leaves $(3 \pm$ $0.07)$ were observed in plants grown in control. In $100 \%$ untreated sample, shoot length $(3 \mathrm{~cm} \pm 0.71)$, root length $(2.2 \mathrm{~cm} \pm 0.08)$, no. of subroots $(1 \pm 0.02)$, no. of leaves $(2 \pm$ 1.22) were observed. In $100 \%$ biotreated sample, shoot length $(5.6 \pm 0.8)$, root length $(4 \pm 0.82)$ no. of subroots $(4.5$ $\pm 0.8)$ and no. leaves $(3 \pm 0.71)$ were recorded.

On the $20^{\text {th }}$ day, shoot length $(10.5 \mathrm{~cm} \pm 0.08)$, root length $(4.8 \mathrm{~cm} \pm 0.01)$, no. of subroots $(6 \pm 0.92)$, no. of leaves $(5 \pm$ $0.09)$ were observed in plants grown in control. In $100 \%$ untreated sample shoot length $(5.1 \mathrm{~cm} \pm 0.7)$, root length $(2.2 \pm 0.08)$ no. of subroots $(2 \pm 1.22)$, no. of leaves $(3.2 \pm$ $0.07)$ were observed. In $100 \%$ biotreated, shoot length (6.2 \pm $0.1)$, root length $(4 \pm 0.2)$ no. of subroots $(4 \pm 0.8)$, no. of leaves $(4 \pm 0.8)$ were observed.

On the $30^{\text {th }}$ day, shoot length $(15.5 \mathrm{~cm} \pm 0.94)$, root length (6 $\mathrm{cm} \pm 0.82)$ no. of subroots $(23 \pm 2.23)$, no. of leaves $(10 \pm$ 0.31 ) were observed in plants grown in control. In $100 \%$ untreated, shoot length $(11.8 \pm 0.07)$, root length $(3.5 \pm 0.72)$ no. of subroots $(15 \pm 0.92)$, no. of leaves $(7 \pm 0.08)$ are observed. In biotreated, shoot length $(12.9 \mathrm{~cm} \pm 0.8)$, root length ( $4 \pm 0.8)$ no. of subroots $(17 \pm 1.24)$, no. of leaves ( 8 $\pm 0.8)$ were observed. The presence of toxic substances present in effluent has decreased the growth of Chrysanthemum sp. exposed to $100 \%$ untreated sample (Mehaytaab, 2008). Whereas increased rate of germination and growth of ornamental plant, Chrysanthemum sp. in 100\% biotreated is due to the maximum removal of toxic substances by the Aspergillus sp. (Prabakar, 1999 and Noorjahan, et al., 2004).
Since Aspergillus species were documented by many workers for their capacity in degrading the effluent, it was selected and was used in biodegradation of flavour effluent. Results of the investigation revealed that the colour and odour of untreated flavour effluent was brick red with unpleasant odour which may be due to presence of large quantity of organic and inorganic pollutants (Singh et al., 1998). But after biodegradation of the effluent for $96 \mathrm{hrs}$, the colour changed to pale yellow with almost odourless condition. This may be due to the action of microbes - Aspergillus sp, which decomposed the toxic pollutants present in the effluent and made the change in colour and odour of the effluent (Krishna priya, 2010). Moreover BOD, COD, TSS, TDS etc present in the effluent were reduced to almost CPCB limit after treatment using Aspergillus sp. Thus from the foregoing discussion it is very clear that microbes play a important role in the biodegradation of organic and inorganic matter.

From the present study, Aspergillus sp, showed efficient degrading capabilities by degrading the contaminants as they use it for their growth and reproduction. Hence after degradation of $100 \%$ untreated flavour effluent, the treated water were used for germination and growth of Chrysanthemum sp. for a period of 30 days using 100\% untreated and biotreated flavour sample.

Seeds of Chrysanthemum sp. when treated with $100 \%$ untreated and biotreated water showed interesting results. Germination and growth of seeds - shoot length, root length, no. of leaves, no. of subroots of Chrysanthemum sp. in $100 \%$ untreated sample on $10^{\text {th }}, 20^{\text {th }}$ and $30^{\text {th }}$ days showed decreased rate of germination as well as the growth of the plant. Whereas maximum germination and growth of plants were recorded exposed to $100 \%$ biotreaed sample and control.

Table 1: Analysis of physico chemical parameters of untreated flavour effluent before (control) and after degradation using Aspergillus sp (96 hours)

\begin{tabular}{|c|l|c|c|c|}
\hline S. No. & \multicolumn{1}{|c|}{ Parameters } & CPCB (1995) & Control (Untreated) & Bio treated \\
\hline 1. & Colour & Colourless & Brown & Pale Yellow \\
\hline 2. & Odour & Odourless & Unpleasant & Odourless \\
\hline 3. & $\mathrm{pH}$ & $5.5-9.0$ & $7.5 \pm 0.08$ & $7.0 \pm 0.3$ \\
\hline 4. & Electrical Conductivity $(\mu \mathrm{mhos} / \mathrm{cm})$ & 400 & $1673 \pm 0.81$ & $700 \pm 3.39(58.15 \%)$ \\
\hline 5. & Total Suspended Solids $(\mathrm{mg} / \mathrm{l})$ & 100 & $378 \pm 1.06$ & $70 \pm 6.81(81.48 \%)$ \\
\hline 6. & Total Dissolved Solids $(\mathrm{mg} / \mathrm{l})$ & 2100 & $2500 \pm 1.49$ & $600 \pm 1.06(76.1 \%)$ \\
\hline 7. & Biochemical Oxygen Demand $(\mathrm{mg} / \mathrm{l})$ & 30 & $292 \pm 4.7$ & $35 \pm 3.68(88.01 \%)$ \\
\hline 8. & Chemical Oxygen Demand $(\mathrm{mg} / \mathrm{l})$ & 250 & $450 \pm 1.29$ & $150 \pm 3.09(66.6 \%)$ \\
\hline
\end{tabular}

$$
\pm=\text { Standard Deviation }
$$

Table 2: Result of the growth of ornamental plant Chrysanthemum sp

\begin{tabular}{|c|c|c|c|c|}
\hline Duration & Parameters & Control & Untreated & Bio-treated \\
\hline $10^{\text {th }}$ Day & Shoot Length & $7 \pm 0.08$ & $3 \pm 0.71$ & $5.6 \pm 0.8$ \\
& Root & $4 \pm 0.01$ & $2.2 \pm 0.08$ & $4 \pm 0.82$ \\
& No. of Leaf & $3 \pm 0.07$ & $1 \pm 0.02$ & $3 \pm 0.71$ \\
& No. of Subroots & $5 \pm 0.71$ & $2 \pm 1.22$ & $4.5 \pm 0.8$ \\
\hline $20^{\text {th }}$ Day & Shoot Length & $10.5 \pm 0.08$ & $5.1 \pm 0.71$ & $6.2 \pm 0.1$ \\
& Root & $4.8 \pm 0.01$ & $2.2 \pm 0.08$ & $4 \pm 0.82$ \\
& No. of Leaf & $5 \pm 0.09$ & $3.2 \pm 0.07$ & $4 \pm 0.8$ \\
& No. of Subroots & $6 \pm 0.92$ & $2 \pm 1.22$ & $4 \pm 0.8$ \\
\hline $30^{\text {th }}$ Day & Shoot Length & $15.5 \pm 0.94$ & $11.8 \pm 0.07$ & $12.9 \pm 0.8$ \\
& Root & $6 \pm 0.82$ & $3.5 \pm 0.72$ & $4 \pm 0.8$ \\
& No. of Leaf & $10 \pm 0.31$ & $7 \pm 0.08$ & $8 \pm 0.8$ \\
& No. of Subroots & $23 \pm 2.23$ & $15 \pm 0.92$ & $17 \pm 1.24$ \\
\hline
\end{tabular}

Volume 6 Issue 1, January 2017 www.ijsr.net 


\section{International Journal of Science and Research (IJSR) \\ ISSN (Online): 2319-7064}

Index Copernicus Value (2015): 78.96 | Impact Factor (2015): 6.391

\section{Conclusion}

The water of good quality and free of pollutants are primary requirements for agricultural and piscicultural practice. Hence from the overall results of the above study, it can be concluded that native fungus, Aspergillus sp. played a key role in the degradation of untreated flavour effluent and the treated water can be utilized for growth of ornamental plant as evidenced in the present work.

\section{References}

[1] Adrianazilly, Jaculien, D.A., Silva. 2011. Influence of $\mathrm{NaCl}$ and $\mathrm{Na}_{2} \mathrm{SO}_{4}$ on kinetics and dye decolorization of crude laccase from Ganoderma lucidum. International Biodeterioration and Biodegradation, 65: 640-644.

[2] Akthar, N.M. and Mohan, P.M.1995. Bioremediation of toxic metal ions from polluted lake waters and industrial effluents by fungal biosorbent. Current. Sci. 69(12): 1028-1030.

[3] APHA. 1995. Standard methods for the examination of water and waster water. American Public Health Association, Washingtom, DC. $17^{\text {th }}$ ed.

[4] CPCB. 1995. Status report of groundwater quality in problem areas. Central Pollution Control Board, Delhi.

[5] Goel, P.K. 1997. Water pollution, causes, effects and control. New Age International (P) Ltd., publishers, New Delhi, 269.

[6] Ihsan Flayyih Hasan AI-Jawhari, Noor Jabar Mhail and Saher Abed AI-Rutha Ali, 2015.Efficiency of some filamentous fungi to treatment of effluent petroleum wastewaters

from refinery.Int.J.Curr.Microbiol.App.Sci.,4(4): 625-641.

[7] Jamuna, S. 2008. Treatment of sewage waste water using aquatic plant, water hyacinth - Eichhornia sp. and its reuse for culture, growth, histopathology and Biochemistry of fish, Tilapia mossambica. B.Sc., Disertation, University of Madras.

[8] Kannagi, S. 2007. Physico-chemical characteristics and identification of microbes of untreated brewery effluent and its treatment using native fungus - Aspergillus niger, aquatic plant, water hyacinth - Eichhornia sp. and green mussel - Perna viridis, M.Sc., Dissertation, University of Madras.

[9] Kowsalya.R, Noorjahan,C.M, Karrunakaran,C.M, Deecaraman,M and M.Vijayalakshmi,2015. Physicochemical characterisation of brewery effluent and its degradation using native fungus Aspergillus niger. Jr. of Industrial Pollution Control., 26 (2):171-176.

[10] Krishna Priya, E. 2010. Biodegradation of Tannery Effluent using native fungus, Penicillium sp. B.Sc., Dissertation University of Madras.

[11] Kulkarni, R.T. 1992. Source and characteristics of dairy wastes from a medium sized effluent on microorganisms, plant growth and their microbial change. Life. Sci. Adv., 3:76-86.

[12] Mehaytaab, M.S. 2008. Treatment of sewage waste water using aquatic plant, water hyacinth - Eichhornia sp. and its reuse for germination, growth and biochemistry of ornamental plant, Impatiens balsamina (Balsam) and edible green leafy vegetable Amaranthus viridis (Arakeerai), B.Sc., Dissertation, University of Madras.
[13] Ninnekar, H.Z. 1992. Biodegradation of environmental pollutants. Environ. Biodeg. 2(5): 149-154.

[14] Noorjahan, C.M., Dawood Sharief, S. and Nausheen Dawood. 2004. Characterization of dairy effleunt. Jr. of Indus. Pollut. Cont., 20(1): 131-136.

[15] Onions, A.H.S., Allsopp, D. and Egginns, H.O.W. 1981. Smith's introduction to industrial mycology, Edward Arnold Publishers Ltd. ( $7^{\text {th }}$ ed).

[16] Prabakar, K. 1999. Studies on Bikoremediation of sugar and distillery effluent. Ph.D. Thesis, University of Madras.

[17] Robinson, R.A. and Stokes, R.H. 1959. Electrolyte Solutions, $2^{\text {nd }}$ (ed.), Academic Press, New York, P.466.

[18] Shafiquzzaman Siddiquee, Kobun Rovina, Sujjat Al Azad, Laila Naher, Saallah Suryani and Pasicha Chaikaew, 2015. Heavy metal contaminants removal from wastewater using the potential filamentous fungi biomass: a review. J Microb Biochem Technol.,7:384393

[19] Singh, S.M., Varshneya, I. and Nagarkoti, M. 1998. Assessment of physico chemical parameters of effluents of three factories of bareilly district and their possible effects on grazing animals and cereals. J. Environ. Biol. 19(3): 271-274.

[20] Thakur, I.S. 2006. Industrial Biotechnology: Problems and Remedies, I-K. International Pvt. Ltd., New Delhi, P. 142-183.

\section{Author Profile}

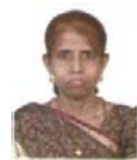

C. M. Noorjahan holds a Master of Science (M.Sc), Master of Philosophy (M.Phil) and Doctor of Philosophy $(\mathrm{PhD})$ degree in Zoology. She is currently an Assistant Professor, at PG \& Research Department of Zoology, Justice Basheer Ahmed Sayeed College for Women (Autonomous), Chennai - 600 018, Tamil Nadu, India.

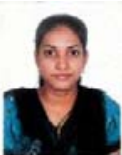

Sheeba Ali Siddiqui holds a Master of Science (M.Sc) and Master of Philosophy (M.Phil) degree in Applied Microbiology and is currently pursuing Doctor of Philosophy (PhD) degree in Microbiology at PG \& Research Department of Zoology, Justice Basheer Ahmed Sayeed College for Women (Autonomous), Chennai - 600 018, Tamil Nadu, India. 